PARADIGMAS DO ENSINO JURÍDICO NO PROCESSO DE GLOBALIZAÇÃO

ATUAL

\author{
Nazaré Portilho Amaral Castro* \\ Cláudia Regina de Oliveira Cantanhede ${ }^{* *}$
}

\title{
RESUMO
}

Este artigo tem como objetivo analisar os paradigmas que norteiam o ensino jurídico no Brasil e as tendências necessárias à formação discente para o século XXI, tendo em vista o processo de globalização. Urge nos espaços em sala de aula o desenvolvimento e compromisso efetivo com práticas que superem a dimensão compartimentalizada, dogmática e procedimentalista do fazer o Direito. Foi realizado um estudo da literatura e da legislação federal que aponta a necessidade de formação profissional com ênfase na postura crítica e reflexiva para com a Ciência do Direito.

Palavras-chave: Direito; Paradigmas; Ensino Jurídico; Globalização; Metodologias Ativas.

\section{PARADIGMS OF LAW TEACHING IN THE PROCESS OF GLOBALIZATION}

\begin{abstract}
This paper aims at analysing the paradigms which guides the law teaching in Brazil and the necessary tendences to the student formation for the XXI century, in view of the globalization process. In the school room it is necessary to get a development and an effective commitment as to practices which go beyond the compartimentalized, dogmatic and proceduralist dimension of doing the Law. It was performed a study of the literature and the federal legislation which points out the need of professional formation emphasizing the critical and reflexive stance regardin the Law Science.
\end{abstract}

Key-words: Law; Paradigms; Law Teaching; Globalization; Active Methodologies.

\section{INTRODUÇÃO}

\footnotetext{
* Graduada em Pedagogia. Graduada em Direito. Mestra em Ensino em Ciências da Saúde. Pós-graduação em Direito Público. Pós-graduação em Nutrição e Saúde aplicada à Prática Pedagógica. Pedagoga do Núcleo de Apoio ao Docente e Discente (NADD) da Universidade Ceuma. E-mail: nazareportilho@ yahoo.com.br

** Graduada em Ciências Sociais. Graduada em Direito. Mestra em Educação. Professora na Universidade Ceuma. E-mail: c.r.back@bol.com.br
} 
No cenário do ensino superior, especificamente direcionado aos cursos de graduação em Direito, vivencia-se um momento em que a Globalização, o Capitalismo, as estruturas sociais e políticas, que subjazem no país, provocam reflexões sobre os paradigmas que envolvem o contexto contemporâneo educacional. Acredita-se que os reflexos dos paradigmas norteadores do ensino incidem diretamente no processo de produção de conhecimento.

Com as exigências da formação acadêmica, percebe-se que os paradigmas educacionais, que norteiam os cursos de Direito no Brasil, muitas vezes entram em choque com a dimensão das habilidades e competências delineadas pelas Diretrizes Curriculares Nacionais e as macrodimensões dos avanços capitalistas.

Na análise realizada neste trabalho no campo teórico-conceitual, não houve a pretensão de trazer diagnósticos e soluções simplistas, mas, sim, realizar uma leitura mais detida e realista do âmbito no qual se vê inserida a educação jurídica. Tem-se a preocupação em clarificar a concepção de produção de conhecimento adotada pelo método tradicional de ensino jurídico e a perspectiva dialético-crítica do ensino frente às complexidades, pluralidade de mudanças sociais e maior concentração de desigualdade nos meios de produção de capital.

No âmago dessa pertinência infere-se que, diante das pressões do mundo moderno, o paradigma dogmático ou positivista do Direito continua com suas bases sólidas nas Ciências Jurídicas. É uma concepção clássica, que tem seus postulados na Ciência moderna e limiar do século XX com sua preocupação restrita com a norma legal, descolada da realidade histórica e social. Essa tendência, muitas vezes, inibe a capacidade crítica do indivíduo, tida como um importante mecanismo de construção pessoal que favorece a participação comprometida com os anseios da sociedade.

Por outro lado, vivemos em um momento histórico extremamente complexo, contraditório, com a expansão e o vasto domínio da economia de mercado, altamente influenciada pelas novas tecnologias, meios de comunicação que favorecem continuamente redes diferenciadas na busca do conhecimento e que põem em evidência a necessidade de superação do modelo positivista para o paradigma da dialética social do Direito, que se firma enquanto paradigma emancipatório; de crítica às estruturas conservadoras e tradicionais que sedimentam as sociedades excludentes e elitistas, as quais fazem do Direito um instrumento para legitimação dessas estruturas.

Neste século XXI houve um crescimento acelerado dos cursos de Direito no país. E 
aqui se insere a preocupação com o ensino jurídico tendo em vista as mudanças que se fazem necessárias para o empreendimento de novos parâmetros de formação, dos quais não comporta mais a formação de um profissional passivo. Dessa análise, esperam-se subsídios para se pensar em outras abordagens didático-metodológicas que propiciem estudos alternativos para formação jurídica.

Para a investidura deste artigo utilizou-se a pesquisa bibliográfica e a documental. $\mathrm{Na}$ pesquisa bibliográfica foi percorrida a literatura com base em autores como Amaral (2014), Berbel (2011), Castro (2014), Martinez (2003), Wolkmer (2015a, 2015b), Santos (2002), José Sobrinho (2005), Valadares e Magalhães (2015) os quais, dentre outros, definem as bases teórico-metodológicas que priorizam as discussões no âmbito do ensino jurídico e os traços que o caracterizam, a fim de possibilitar-se uma leitura das concepções paradigmáticas existentes.

$\mathrm{Na}$ pesquisa documental foi analisada a Constituição Federal Brasileira (BRASIL, 1988), a Lei de Diretrizes e Bases da Educação Nacional- LDB (BRASIL, 1996), as Diretrizes Curriculares Nacionais-DCNs (BRASIL, 2004), com propostas e direcionamento, que, paralelamente, reforçam o desenvolvimento de um processo educativo favorável às discussões e reflexões críticas que visam a formação jurídica mais ampla.

O presente trabalho encontra-se estruturado buscando discutir, na primeira seção, o paradigma dogmático ou positivista, seu surgimento e características; na segunda seção, trata-se da relevância do paradigma dialético ou teoria crítica e, como terceira seção, são tecidas breves considerações sobre a globalização e o ensino jurídico. Por fim, a título de conclusão, apresentam-se os resultados e discussões obtidos com o exame minucioso da literatura e documentos para tecer as reflexões.

\section{O PARADIGMA DOGMÁTICO OU POSITIVISTA}

Essa concepção político-ideológica do fenômeno jurídico se edificou sob a égide do racionalismo cartesiano em que o Positivismo jurídico representava os valores políticoeconômicos do liberalismo burguês laissez faire, laissez passer no plano do Direito. Concepção que considera o Direito aquilo que se encontra formalmente disposto no ordenamento legal, sendo desnecessário qualquer juízo de valor acerca de seu conteúdo (WOLKMER, 2015a).

O paradigma positivista imperou no século XIX incidindo seus reflexos em diversos 
países, entre eles o Brasil, deixando cravadas suas características na forma de conduzir o processo de ensino. A centralidade curricular do paradigma positivista reside na reprodução do corpus do saber jurídico como supremacia dos demais saberes, bastando ao aluno cumprir sua tarefa de reproduzir literalmente o saber ensinado pelo professor em sala de aula. Basta saber a lei e aplicá-la no contexto dado. Na linha de entendimento desse paradigma, é desnecessário saber o contexto de produção da norma jurídica, restringindo a atuação do operador jurídico em conhecer a lei e saber aplicá-la na sua profissão.

Aos poucos esse paradigma, tendo em vista o quadro de mudanças sociais, políticas, econômicas e educacionais, foi perdendo espaço, abrindo o debate em torno de um novo paradigma científico para as Ciências como um todo e, também, para as Ciências Sociais, que, de uma maneira mais específica, o vêm realizando ao longo dos anos. A crise dessa percepção remete à crise dos tempos modernos, na qual a evolução científica, em que nos encontramos, não corresponde mais às premissas do racionalismo cartesiano (SANTOS, 2002).

Verifica-se que o saber científico encontra-se amarrado às crendices das concepções cientificistas e positivistas. Essa estrutura fixa e estável é incapaz de responder às demandas e às novas necessidades educativas de um mundo atual em profundas transformações. Os problemas atuais são problemas sistêmicos que expressam a visão mecanicista, reducionista e fragmentária que aflige, indistintamente, a produção do conhecimento no ensino jurídico e, consequentemente, não atende a essa complexidade contemporânea.

Cumpre observar que as reflexões sobre a crise paradigmática formal ensejaram o surgimento de várias teorias críticas que, através dos seus discursos, procuram desconstruir o paradigma da Ciência jurídica positivista, criando outras bases epistemológicas para a compreensão do fenômeno jurídico. Esta desconstrução vem ocorrendo, à medida em que as reflexões críticas promovem revisões paradigmáticas das matrizes teórico-metodológicas a serem utilizadas (MIKOS; VILLATORE, 2016).

Wolkmer (2015b) apresenta o modelo crítico-interdisciplinar da racionalidade emancipatória como forma epistemológica de suplementação do modelo tradicional de racionalidade da educação tecnoformal.

São imprescindíveis, no ensino jurídico, estudos interdisciplinares que possam envolver a interface com a Pedagogia, a Filosofia, a Psicologia, a Sociologia, a História, as quais são áreas de conhecimento que servirão para trazer lucidez e a compreensão dos fenômenos que envolvem às práticas de um país em desenvolvimento (RODRIGUES; 
ARRUDA, 2012).

Nesse passo de estudos interdisciplinares, há mais possibilidades de reflexão a respeito dos direitos humanos, da solidariedade e da responsabilidade cidadã e com o país, vislumbrando uma formação em que as injustiças sociais poderão ser minimizadas e a sociedade caminhará em rumos de novas perspectivas (FEFERBAUM; GHIRARDI, 2012).

Em meio ao caos de instabilidade e euforia social, político e econômico, o qual se instalou no país, essa possibilidade somente poderá acontecer com as premissas práticas de mecanismos de ações concretas democráticas e de respeito a liberdade, dignidade e a igualdade de todos. O Direito abriga a Justiça, a anticorrupção e o respeito às normas necessários impostas por ele como justas, levando-se em conta as características e direitos fundamentais de todos os seres humanos, conforme preconiza a Constituição Federal (BRASIL, 1988).

Embora o país tenha delineado sua história no ensino jurídico, construindo-o sobre a matriz de ideais liberais, baseado na adoção de currículos privatistas e metodologias pedagógicas tradicionais, tem havido um movimento de educadores comprometidos nos cursos de Direito na realização da tarefa de reconstrução e atualização das universidades para atender com eficácia às novas demandas da atualidade (MARTINEZ, 2003).

Concorda-se com Santos (2002), quando destaca o estudo do campo da Hermenêutica e da interpretação, da Retórica, da Linguagem e da Argumentação como forma de atenuar as lacunas da crise epistemológica do conhecimento e buscar desvelar as estruturas conservadoras.

Nesse contexto, convém relembrar a tríade que dá sustentação à universidade: Ensino, Pesquisa e Extensão. Em contraposição ao que se observa em muitas instituições de ensino superior, entende-se a pesquisa como elemento integrante do Ensino. A Pesquisa, além de fazer parte da formação do professor, é também imprescindível para o desenvolvimento e formação do aluno.

A Lei no 9394/96 - Lei de Diretrizes e Bases da Educação Nacional (LDB) traz a temática infra. In Verbis:

Art. 43 - A educação superior tem por finalidade:

III - incentivar o trabalho de pesquisa e investigação científica, visando o desenvolvimento da ciência e da tecnologia e da criação e difusão da cultura, e, desse modo, desenvolver o entendimento do homem e do meio em que vive; [...] (BRASIL, 1996).

Tendo em vista o que diz a Legislação, a Educação Superior, de forma geral (em 
Instituições de Ensino Superior credenciadas ou não como universidades), tem por finalidade incentivar o trabalho de pesquisa e investigação científica. Ou seja: a obrigatoriedade da pesquisa não se restringe às universidades.

Quando há integração entre Ensino e Pesquisa nas atividades do professor e dos alunos, ocorre melhoria do ensino e, consequentemente, da formação do profissional, permitindo formar sujeitos autônomos, participativos e críticos, capacitados a refletir e produzir novos conhecimentos acerca de sua prática profissional.

A Resolução do Conselho Nacional de Educação/Câmara de Educação SuperiorCNE/CES n. ${ }^{\circ}$ 9/2004, a qual trata das Diretrizes Curriculares Nacionais (DCN), em seu artigo $2^{\circ}, \S 1^{\circ}$, inciso VII, estabeleceu que o projeto pedagógico do curso, além da clara concepção do curso de Direito, enseja seu currículo pleno e sua operacionalização, os quais abrangerão, sem prejuízo de outros, o incentivo à Pesquisa e à Extensão, como necessário prolongamento da atividade de ensino e como instrumento para a iniciação científica (BRASIL, 2004).

Ademais, no Art. $3^{\circ}$ das DCN encontram-se os dispositivos, relativamente ao perfil que se espera de seus egressos e às habilidades e competências que devem possuir, dos quais

[...] o curso de graduação em Direito deverá assegurar, no perfil do graduando, sólida formação geral, humanística e axiológica, capacidade de análise, domínio de conceitos e da terminologia jurídica, adequada argumentação, interpretação e valorização dos fenômenos jurídicos e sociais, aliada a uma postura reflexiva e de visão crítica que fomente a capacidade e a aptidão para a aprendizagem autônoma e dinâmica, indispensável ao exercício da ciência do Direito, da prestação da justiça e do desenvolvimento da cidadania (BRASIL, 2004).

O texto legal referido acima estabelece a exigência do incentivo à Pesquisa em todas as etapas do ensino superior, e percebe-se que, nos cursos de Direito, se institucionalizam através das diretrizes curriculares, também essa necessidade.

Com fulcro nesses posicionamentos, enseja-se a seguir a discussão acerca dos processos de desenvolvimento de uma educação jurista que contemple uma dialética dentro da tessitura complexa e contraditória da sociedade.

\section{O PARADIGMA DIALÉTICO OU TEORIA CRÍTICA NO ENSINO DO DIREITO}

Esse movimento dialético não é novo: emergiu desde a Antiguidade Clássica. Destarte, mesmo sendo empreendido além dos tempos, ainda vem consolidando-se e 
buscando espaços na universidade frente às mudanças e com as constantes alterações na sociedade e na legislação.

Em face dessa realidade extremamente inconstante e emergente, que muda frente às constantes alterações sócio-políticas e econômicas, cumpre considerar-se que se vivencia, na atualidade, uma das fases mais dicotômicas do Capitalismo avançado (dificuldades econômicas, grande concentração de corporações internacionais, formação de blocos econômicos e integração de mercado, desnivelamento das riquezas do país, estas concentradas cada vez mais nas mãos de poucos).

Assim sendo, essa realidade aparente implica ser necessário revisitar-se um novo modo de conceber, entender e praticar o Direito. Essas exigências recaem sobre a Ciência jurídica em seu aspecto epistemológico, pois ocorrem transformações no seu objeto, alterações na maneira de interpretá-lo, analisá-lo e de estabelecer conexões.

Com a evolução das relações sócio-jurídicas, sobretudo no ponto de vista do Direito público, com ênfase na relação Estado-indivíduo, a democratização dos processos decisórios, com vistas à consolidação da Cidadania e da Democracia efetivamente participativas na crise estrutural, torna-se momento propício para a aplicabilidade de novas concepções e paradigmas do Direito.

Frise-se que, embora ainda se encontrem arraigados no meio acadêmico os métodos de inspiração positivistas e mesmo sendo um instrumento de aplicabilidade incisiva do Direito, suas amarras e limitações não dão mais conta da extraordinária demanda de produção do conhecimento jurídico.

Ademais, essa visão entra em contramão com as vias de desenvolvimento social, político e de novos saberes jurídicos que se emanam constantemente. Há uma luta interna, que ganha cada vez mais espaço para impedir o retorno ao Estado de arbitrariedade estatal típica do Absolutismo, ao qual não mais se presta à interpretação e aplicação judiciais do Direito em face das novas e sucessivas ordens constitucionais e legais que embasam os Estados modernos.

A evolução constante das relações jurídicas, concebidas em sua complexidade, exige uma teoria crítica consistente no modo de encarar o Direito como prática social específica, na qual estão expressos historicamente os conflitos, os acordos e as tensões dos grupos sociais que atuam em uma formação social determinada (COELHO, 2003).

Depreende-se que o conhecimento jurídico é parte do conhecimento da formação social em sua totalidade e de suas transformações na história, tendo o labor hermenêutico, como 
não sendo uma tarefa puramente técnica ou analítica, mas, sobretudo, política, alimentada pelas contribuições da hermenêutica jurídica contemporânea (COELHO, 2003).

Coelho (2003) enfatiza que o papel da Dialética social ou Teoria crítica do Direito é atingir não apenas a Teoria Geral do Direito, mas também todas as disciplinas inseridas numa perspectiva sociológica para que seja suprida a ausência do direito popular na lei do Estado. A teoria crítica tem suas bases epistemológicas em John Dewey e Paulo Freire, defensores da dialética da participação, uma forma de alcançar a libertação humana.

Entendem-se as Ciências Jurídicas como um processo de libertação permanente, equidade social, na medida em que é uma construção, na qual as classes oprimidas constroem sua libertação frente às classes opressoras, de tal forma que o Direito possa compreender uma construção histórica que continua sendo um processo no qual são buscadas sempre novas expressões de Justiça e Cidadania.

Com base nessas considerações, pode-se inferir que o Direito e sua função na sociedade vêm sendo analisados em várias perspectivas. Contudo, a que enfocamos é a da dimensão emancipatória do direito, oriunda da elaboração da teoria jurídica crítica.

A teoria crítica das Ciências Jurídicas se efetiva na construção de um Direito capaz de proporcionar condições de atendimento às demandas sociais e à efetivação das garantias constitucionais.

Para Clève (2001), a teoria crítica não pode limitar-se a criticar o Direito instituído no ordenamento legal, mas buscar construir uma teoria jurídica crítica que resgate a dimensão política do direito, a fim de concretizar as demandas sociais, as garantias constitucionais e a dignidade da pessoa humana, conforme disciplina a Constituição Federal.

As influências desse paradigma epistemológico no currículo são significativas e mudam radicalmente a forma de pensar e processar o saber jurídico em sala de aula. O primeiro ponto a destacar é que não verá o saber jurídico como corpo curricular constituído de saberes não interessados e desprovido de caráter ideológico, mas reconhece que estes reproduzem os valores dominantes ao manter o engessamento da norma jurídica e sua hierarquia como posição de neutralidade e cientificismo.

Observa-se, portanto, a necessidade de superação da crise vivenciada pelo ensino jurídico para integrar a nova realidade em que está inserida a sociedade em um mundo globalizado. 


\section{BREVES CONSIDERAÇÕES SOBRE A GLOBALIZAÇÃO E O ENSINO JURÍDICO: dilemas e alternativas}

Pode-se afirmar que as transformações ocasionadas pelo processo de globalização têm provocado impactos no âmbito social, político, cultural e predominantemente o econômico. As universidades, enquanto instituições centrais da sociedade, totalmente relacionadas às mudanças do mundo, evidentemente, estão envolvidas nesse processo.

Inicialmente, pode-se expressar, de uma maneira geral e sucinta, que não existe uma definição única e universalmente aceita para a globalização: o termo na verdade recebe várias interpretações e enfoques, sendo considerado um fenômeno que não é recente, porém que ganhou maior expressividade no século XX entre os anos de 60 e 70, tendo em vista a “[...] rápida expansão de interdependência política e econômica - muito especialmente entre as nações ocidentais". (HELD; McGREW, 2001, p.9). Apresenta aspectos positivos, proporcionados pelos avanços tecnológicos e científicos, mas de acesso desigual, favorecendo os países ricos em detrimento dos países periféricos. Com um caráter multifacetado, contraditório e complexo e de consequências ainda incertas. Nesse sentido, Estevão (2002, p. 09) considera que a globalização é: “[...] um fenómeno complexo que mobiliza um conjunto de fatores multidireccionais de ordem econômica, política e cultural, cujos efeitos não deixam igualmente de ser problemáticos em termos de natureza, de magnitude ou de resultados”.

Já Libâneo, Oliveira e Toschi (2006, p. 74) afirmam que

O capitalismo lançou-se, no final do século XX, em um acelerado processo de
reestruturação e integração econômica, que compreende o progresso técnico-
científico em áreas como telecomunicações e informática, a privatização de amplos
setores de bens e serviços produzidos pelo Estado, a busca de eficiência e de
competividade e a desregulamentação do comércio entre países, com a destruição das
fronteiras nacionais e a procura pela completa liberdade de trânsito para pessoas,
mercadorias e capitais, em uma espécie de mercado universal. Esse processo de
aceleração, integração e reestruturação capitalista vem sendo chamado de
globalização.

Ao conceituarmos globalização, considerada como um novo paradigma de superação do paradigma clássico fundado estritamente na reflexão sobre a sociedade nacional, para o da sociedade global, vimos que ela exige novos padrões estruturais, tendo em vista a busca pela eficiência, a competitividade, o desenvolvimento e a necessidade do domínio de novos 
conhecimentos e da tecnologia proporcionada por este fenômeno. Nesse sentido a Educação superior tornou-se estratégica dentro da visão de modernidade globalizada, ao habilitar o maior número possível de trabalhadores em maiores quantidades de conhecimentos. Evidentemente, todas essas mudanças afetam diretamente a seara do Direito, demonstrando a incapacidade, por parte da dogmática jurídica positivista já estudada, de captar e responder perante os fatos novos que surgem dessas transformações e de outra parte exigiu e ainda exige a revisão de seus paradigmas.

A crise, no entanto, não se restringe a paradigmas: existe uma crise institucional que perpassa as universidades, e, consequentemente os cursos de Direito, conforme alerta José Sobrinho (2010). De um lado assistimos à Educação visando a melhoria da vida dos cidadãos com pertinência ética, comprometida com a formação de cidadãos autônomos e com o aprofundamento da Democracia, e nesse intuito ressaltamos a importância e as contribuições possíveis da teoria crítica no ensino do Direito; e de outro, a crescente pressão nos critérios de eficácia e de produtividade de natureza empresarial de uma economia globalizada. Nas palavras de Muhl (1999, p. 27), atualmente observa-se também uma educação que se tornou “[...] um instrumento de condicionamento e de adestramento dos indivíduos aos interesses econômicos e ideológicos prevalecentes".

Como já discorrido, o Ensino Superior deveria fundamentar-se no trinômio EnsinoPesquisa-Extensão. Isto parece ocorrer mais nas instituições públicas e em algumas instituições privadas, mais voltadas para a formação de docentes e discentes, na divulgação de conhecimento, na promoção da Ciência e no trabalho junto a comunidade. Porém Cunha (2007) e Barreto e Leher (2008) apontam que a ênfase da maioria das instituições privadas fundamentase, na realidade, em atender às necessidades de mão de obra do mercado de trabalho e o foco principal não seria a produção de conhecimento, mas, sim ter mais alunos e mais lucro, atuando como Organizações/Empresas que visualizam a educação como um serviço, com um fim que não é em si mesmo, mas voltado para o mercado.

Corroborando as críticas supracitadas, colhe-se a seguinte reflexão de José Sobrinho (2010, p. 24)

[...] em boa parte, a educação superior estaria deixando de ter como referência o desenvolvimento da sociedade e a formação da consciência crítica de cidadãos e estaria elegendo como finalidades principais a autonomização técnica, a competitividade individual, a instrumentalização econômica, a operacionalidade profissional. 
Ao tratarmos mais especificamente sobre o tema Globalização e o ensino do Direito em nosso país, consideramos importante identificar, de forma sintética, a partir das ideias de Duncan Kennedy (apud CASTRO, 2014), três ondas de "globalização" do direito: 1) pensamento jurídico clássico (primeira globalização, 1850-1914); 2) o "social” (segunda globalização, 1900-1968); e 3) direito operacional - eclético, terceira globalização, 1945-2000).

Faz parte, segundo Kennedy (apud CASTRO, 2014), da construção intelectual e prática da primeira onda do Direito globalizado o estabelecimento de noções e doutrinas jurídicas de caráter altamente formalista e positivista. Nesse sentido, a partir do presente trabalho, foi possível identificar a influência e importância do paradigma positivista no Brasil durante o século XIX.

Já a segunda Globalização, conforme Castro (2014), no caso específico do Brasil no período histórico referenciado, resultou em importações e adaptações de doutrinas e orientações metodológicas parciais e limitadas, não trazendo mudanças significativas no ensino do direito, sua prática profissional ou na estrutura de instituições herdadas da primeira globalização do direito. Não obstante, cabe ressaltar um aspecto positivo no plano metodológico dessa segunda onda que foi a abertura do Direito para o diálogo interdisciplinar, com a valorização de disciplinas como a sociologia, a economia e a psicologia.

E, por fim, as características da terceira onda de Globalização do Direito podem ser assim resumidas por Castro (2014): a supremacia do judiciário, o recurso a principiologias e o exercício da ponderação de valores. Para esse teórico, esta globalização também pode ser convenientemente considerada como tendo um caráter operacional-eclético, “[...] por recorrer a legados de ambas anteriores ondas de globalização do direito, sem alcançar ou buscar um caráter conteudístico próprio". (CASTRO, 2014, p. 56). No Brasil, a partir de 1988, essa onda do Direito repercutiu, segundo esse autor, para vários programas de pós-graduação, para algumas disciplinas da graduação, como discussões de Direito internacional e para setores das profissões jurídicas.

Ao analisar as três globalizações do direito, Kennedy (2006) conclui que constituem na verdade três ciclos de influência e propagação global de ideias jurídicas, sobretudo, alemãs (presentes na primeira globalização), francesas (segunda globalização) e mais recentemente, após 1950, como terceira globalização, estadunidense. O atual modelo prevalecente de educação superior dos Estados Unidos da América pode ser explicado por sua liderança 
tecnológica e econômica no mundo, dois fatores que impulsionaram o estreitamente funcional da Educação Superior com a Indústria e a Economia globalizada. (JOSÉ SOBRINHO, 2010); de igual forma, Castro (2014, p. 57) ressalta e conclui que esse direito operacional-eclético, da terceira globalização, é um direito a serviço dos interesses do mundo do comércio e das finanças globais, ou seja:

[...] o 'direito global' positivado de hoje é composto de quadros normativos (regimes internacionais, normas constitucionais, decisões judiciais, regramentos) e meios de análise que, em seu conjunto, servem para dar suporte jurídico aos interesses de grandes organizações globais - paradigmaticamente, as entidades que impulsionam o comércio e as finanças globais.

Evidenciam-se, assim, vários dilemas. As instituições de ensino superior, particularmente as do curso de Direito, precisam rever suas formas de organização e de ensino, buscando acompanhar as mudanças impostas pela globalização e a formação adequada de profissionais para mercado.

No caso de países periféricos como o Brasil, ainda precisamos enfrentar outros problemas graves a exemplo de diminuir os atrasos educacionais, as deficiências no campo tecnológico e aprofundar a vida democrática. Sendo assim, torna-se inevitável uma maior atenção à Justiça social e menos subserviência aos interesses do mercado. Em um momento com tantas transformações importa, igualmente, entender, interpretar e apontar soluções para os problemas atuais, sendo fundamental o desenvolvimento de pesquisas, bem como o desenvolvimento teórico, baseado em uma formação crítica, reflexiva e ética. Acreditamos, que o cumprimento das Diretrizes Curriculares Nacionais e a Teoria Crítica no Ensino do Direito, já discutidas no presente trabalho, serão de extrema valia e fundamentais nesse sentido.

Transpondo essa análise apresentada para o mundo acadêmico do Direito, é relevante, igualmente, que no ensino das Ciências Jurídicas os docentes incorporem uma postura didática que se comprometa em desvelar as estruturas dominantes e questionar os arranjos que formatam a estrutura social dominante do saber jurídico. Para seu desvelamento, cumpre historicizar-se o saber jurídico cristalizado no currículo, dar uma nova dinâmica a partir das múltiplas determinações da prática social. São as práticas sociais que determinarão a modelação e a formatação do saber jurídico. Daí a importância de se estudar o saber jurídico a partir da práxis social.

O currículo dos cursos de graduação em Direito precisa ser analisado na produção de 
uma formação profissional crítico e reflexivo, no qual a estrutura dos cursos se organizem a partir dele. A lente analítica só será possível quando aquele, que traduz o currículo e o saber jurídico corporificado em sala de aula, o fará a partir da crítica ao sistema capitalista que produz formas de dominação e de desigualdade. Contrapomo-nos ao caráter alienador do saber jurídico na direção de se buscar formas alternativas de aplicação da norma jurídica coerentes com o princípio da justiça social.

A Resolução CNE/CES nº 09/2004, ao instituir as Diretrizes Curriculares Nacionais aos cursos de Direito, dispõe, no Art. $5^{\circ}$, de conteúdos e atividades pertinentes a três eixos de formação: fundamental, profissional e prática (BRASIL, 2004).

Para cumprir plenamente a formação de um profissional, esses eixos articulam-se com as habilidades e competências básicas, as quais não se cingem ao conhecimento e práticas das técnicas dogmáticas, mas abrangem um contexto plural, holístico do ser do Direito, que é construído de forma integrada e coerente com as necessidades do sistema educativo. Consideremos: I-Leitura, compreensão e elaboração de textos, atos e documentos jurídicos normativos, com a devida utilização das normas técnico jurídicas; II-Interpretação e aplicação do Direito, III-Pesquisa e utilização da legislação, jurisprudência, da doutrina e de outras fontes do Direito; IV-Adequada atuação técnico-jurídica, em diferentes instâncias, administrativas ou judiciais, com a devida utilização de processos, atos e procedimentos; V-Correta utilização da terminologia jurídica ou da ciência do Direito; VI-Utilização de raciocínio jurídico, de argumentação, de persuasão e de reflexão crítica; VII-Julgamento e tomada de decisões; VIIIDomínio de tecnologias e métodos para permanente compreensão e aplicação do Direito (BRASIL, 2004).

Cumpre reconhecer-se que, diante dessas habilidades e competências, são colocados desafios à universidade quanto à formação de um profissional em construção permanente.

Nesse panorama situam-se novos desafios e perspectivas do ensino superior dos cursos de Direito. Identificam-se às práticas educativas novas metodologias ativas à Educação, as quais assumem a construção do conhecimento como traço definidor da apropriação da informação e confronto com a realidade, ou seja: damos ênfase a serem utilizadas nos espaços educativos as metodologias problematizadoras. Estas surgem como alternativas ao ensino tradicional, que parecem não trazer uma explicação, discussão mais aprofundada da realidade, ao menos como único método de ensino, diante das exigências do mundo moderno.

As metodologias ativas buscam caminhos para o desenvolvimento da autonomia 
profissional, a autodeterminação do aluno, pessoal e social. Portanto, indispensáveis para o desenvolvimento da consciência crítica, com o propósito de refletir sobre a realidade. Assim, a motivação do aluno passa a ser o ponto central de todo o processo de ensino-aprendizagem. $\mathrm{O}$ docente, nesse contexto, revela-se um parceiro, um motivador e um catalisador desse processo (AMARAL, 2014).

Essa concepção metodológica tem suas bases em um princípio teórico significativo: a autonomia, premissa de desenvolvimento humano explicitada nos estudos de Paulo Freire. Ainda com Freire, propõe-se a Educação numa perspectiva libertadora, salientando-se que o educador ponha em prática sua capacidade de autogerenciar ou autogovernar seu processo de formação.

As metodologias ativas de ensino integram-se a processos de conhecimento, análise, estudos, pesquisas e decisões individuais ou coletivas, com a finalidade de encontrar soluções para um problema. Nessa realidade metodológica, o docente atua como facilitador ou orientador para que o estudante faça pesquisas, reflita e decida por ele mesmo o que fazer para atingir os objetivos estabelecidos (BERBEL, 2011).

Com fundamento nas reflexões e teia de saberes situados nessa linha de atuação didático-metodológica, compreendemos que as metodologias ativas baseiam-se em formas de desenvolver o processo de aprender, utilizando experiências reais ou simuladas, visando às condições de solucionar desafios oriundos das atividades essenciais da prática social, em diferentes contextos.

Para fins didáticos em sala de aula, as metodologias ativas aproveitam a problematização como estratégia de ensino/aprendizagem, com o objetivo de alcançar e motivar o aluno, pois diante do problema ele se detém, examina, reflete, relaciona a sua história e passa a ressignificar suas descobertas.

\section{CONCLUSÃO}

Em meio às atuais complexidades do mundo moderno, o Positivismo jurídico ainda exerce forte influência no meio jurídico, seja na Universidade, seja nas Instituições do Poder Judiciário. Observa-se na realidade social cotidiana que o Direito, posto em prática, muitas vezes não é o Direito proposto pelos órgãos responsáveis pela sua elaboração e cumprimento. Percebe-se um descompasso entre os anseios da sociedade, o que a legislação traz e a efetivação 
prática do Direito.

Aprender as Ciências Jurídicas não é memorizar normas legais, postulados e técnicas jurídicas, tampouco simplesmente reproduzir os dogmas, as teorias e a letra da lei. Aprender Direito é mais que isso: vai além da retórica e do utilitarismo; é saber que o mundo atual é complexo, assim como nosso país, cheio de conflitos, desafios e carências que precisam ser postos no debate democrático. Ao contrário dessa práxis, aprender Direito envolve problematizar a realidade. É partindo dessa premissa, de reflexão da Verdade e Justiça social, que a mediação do saber jurídico em sala de aula apontará caminhos para a construção do conhecimento jurídico.

Como já discorrido, os efeitos do processo de globalização já se encontram no plano jurídico e no ensino do Direito, carecendo de uma formação profissional mais ampla, interdisciplinar, numa perspectiva crítica e responsável quando se busca, frente ao mundo, entendê-lo e usar os argumentos jurídicos apreendidos de modo transformador, coerente com as percepções de cada caso e não somente responder as demandas de mercado.

Entende-se que o ensino de Direito seja o espaço de formação de operadores jurídicos críticos e de juristas comprometidos com os valores sociais hegemônicos calcados na Justiça os quais buscam, através de um exercício da crítica, implementar novas práticas no âmbito de atuação profissional.

Há necessidade de dar-se atenção especial às Diretrizes Curriculares Nacionais para os cursos de Direito, pois estas apresentam competências e habilidades que deverão estar sincronizadas com o currículo dos cursos de graduação em Direito, de forma a provocar mudanças de mentalidade e reflexos sociais posteriormente.

Ressalte-se também a importância do desenvolvimento da utilização das metodologias ativas ou de outras possibilidades metodológicas que sejam coerentes com as características de uma formação profissional mais heterogênea.

Com base nessa discussão, afirma-se que não há mais espaço para acadêmicos e profissionais do Direito sem as mínimas condições para o exercício das competências e habilidades inerentes à argumentação, à criticidade e à busca por soluções jurídicas para seus clientes. Considera-se ser esse um caminho honrado, ético e moral para o desenvolvimento profissional participativo, responsável com os anseios da sociedade e que contemple o efetivo Direito da legislação brasileira. 


\section{REFERÊNCIAS}

AMARAL, Larissa M. do. Entre cativar e qualificar: os desafios do professor de direito por uma abordagem dos métodos de ensino participativo. In: CONGRESSO NACIONAL CONPEDI- DIREITO, EDUCAÇÃO E METODOLOGIAS JURÍDICOS, 12., 2014. [S.1.]. Anais... [S.1.: s.n.], 2014. Disponível em: <http://www.publicadireito. com.br/artigos/? cod=670f0c94cc5271fe >. Acesso em: 15 maio 2016 .

BARRETO, R.G.; LEHER, R. Do discurso e das condicionalidades do Banco Mundial, a educação superior "emerge" terciária. Revista Brasileira de Educação, v. 13, n. 39, p. 423-436, 2008.

BERBEL, N.A. N. As metodologias ativas e a promoção da autonomia de estudantes. Semina: Ciências Sociais e Humanas, Londrina, v. 32, n. 1, p. 25-40, jan./jun. 2011.

BRASIL. Conselho Nacional de Educação. Câmara de Educação Superior. Resolução CNE/CES n ${ }^{\circ}$ 9, de 29 de setembro de 2004. Institui as Diretrizes Curriculares Nacionais do Curso de Graduação em Direito e dá outras providências. Brasília, DF, 2004. Disponível em: <http://portal.mec.gov.br/cne/arquivos/pdf/rces09_04.pdf>. Acesso em: 18 abr. 2016.

Constituição da República Federativa do Brasil de 1988. Brasília, DF, 1988. Disponível em: <http://www.planalto.gov.br/ccivil_03/Constituicao/Constituicao.htm>. Acesso em: 20 abr. 2016.

Lei $\mathrm{n}^{\circ}$ 9.394, de 20 de dezembro de 1996. Estabelece as Diretrizes e Bases da Educação Nacional. Brasília, DF, 1996. Disponível em: <http://www.planalto.gov. br/ccivil_03/leis/L9394.htm>. Acesso em: 18 abr. 2016.

CASTRO, Marcus Faro de. Ideias sobre o ensino jurídico globalizado. Cadernos FGV Direito Rio. Educação e Direito, v. 09, 2014.

CLÈVE, Clèmerson Merlin. O direito e os direitos: elementos para uma crítica do direito contemporâneo. 3. ed. Belo Horizonte: Fórum, 2011.

COELHO, Luiz Fernando. Teoria crítica do direito. 2. ed. Belo Horizonte: Del Rey, 2003.

CUNHA, L.A. O desenvolvimento meandroso da educação brasileira entre o estado e o mercado. Educação e Sociedade, v. 28, n. 100, p. 809-829, 2007.

ESTEVÃO, Carlos V. Globalização, metáforas organizacionais e mudança educacional.. Porto: Asa Editas II, SA, 2002. (Cadernos do CRIAP).

FEFERBAUM, Marina; GHIRARDI, José Garcez (Orgs.). Ensino do Direito para um mundo em transformação. São Paulo: FGV, 2012.

HELD, David; McGREW, Anthony. Prós e contras da globalização. Tradução Vera Ribeiro. 
Rio de Janeiro: Horge Zahar Editora, 2001.

KENNEDY, Duncan. Three Globalizations of Law and Legal Thought: 1850-2000. In.: TRUBEK, David M.; SANTOS, Alvaro (Orgs.), The New Law and Economic Development: a critical appraisal. Cambridge: Cambridge University Press, 2006. p.19-74.

LIBÂNEO, José Carlos; OLIVEIRA, João Ferreira de; TOSCHI, Mirza Seabra. Educação Escolar: políticas, estrutura e organização. 3.ed. São Paulo: Cortez, 2006.

JOSÉ SOBRINHO, Dias. Educação Superior, globalização e redemocratização: qual universidade? Rev. Bras. Educ., Rio de Janeiro, n. 28, jan./abr. 2005.

Dilemas da Educação Superior no mundo globalizado: sociedade do conhecimento ou economia do conhecimento? São Paulo: Casa do Psicólogo, 2010.

MARTINEZ, Sérgio Rodrigo. Manual da educação jurídica. Curitiba: Juruá, 2003.

MIKOS, Nádia R. C.; VILLATORE, Marco A. C. Dos Paradigmas Educacionais e sua Aplicação ao Ensino do Direito. Revista Brasileira de Educação e Cultura, n. 13, jan./jun. 2016.

MUHL, Eldon. Racionalidade comunicativa e educação emancipadora. Campinas: Unicamp, 1999.

RODRIGUES, Horacio Wanderlei; ARRUDA, Edmundo Lima Júnior. (orgs). Educação jurídica 2. ed. Florianópolis: FUNJAB, 2012. (Coleção - Pensando o Direito no séc. XXI. v. II).

SANTOS, André Luís Lopes dos. Ensino jurídico: uma abordagem político educacional. Campinas: Edicamp, 2002.

WOLKMER, Antonio Carlos. História do direito no Brasil. 9. ed. Rio de Janeiro: Forense, 2015a.

Introdução ao pensamento jurídico crítico. 9. ed. São Paulo: Saraiva, 2015b.

VALADARES, Charine Carolina; MAGALHÃES, Carlos Augusto Teixeira. Os rumos do ensino jurídico no Brasil a mudança e a continuidade. Letras Jurídicas, v. 3, n. 2, 2 sem. 2015. 